\section{Scientiam Juris \\ Scientiam Juris}

Out 2015 a Set $2016-v .4-n .1$

\title{
A educação prisional no Mercosul
}

A educação deve ser vista como um direito, não para a reintegração. Claro que isso é muito importante, mas se a reintegração for impossível, a educação continua a ser um direito. Não devemos instrumentalizar a educação unicamente para um papel social ou do tipo político-social. A educação pode ser uma solução se for uma educação ao longo da vida, não apenas do tipo profissional ou a reeducação. É para muitos presos a primeira oportunidade de compreender sua história e de tratar de desenvolver seu próprio projeto de vida. A noção de educação prisional como direito está no auge das discussões em todo o mundo. Em novembro de 2006, por exemplo, o Brasil acolheu, em Belo Horizonte, as discussões do Fórum Educacional do Mercosul, que tinha como um dos núcleos de debates o Seminário de Educação Prisional, que recebeu autoridades neste assunto de toda a América Latina e Europa e de entidades ligadas à educação e direitos humanos. 0 objetivo era criar uma rede latino-americana de discussões, que colocasse na pauta dos governos de cada país a educação prisional como direito inalienável de todos e as possíveis soluções para tornar essa educação mais proveitosa.

Palavras-chave: Educação Prisional; Mercosul; Recuperação de Detentos.

\section{Prison education in Mercosul}

Education should be seen as a right, not for reintegration. Of course this is very important, but if reintegration is impossible, education remains a right. We should not instrumentalize education solely for a social or political-social role. Education can be a solution if it is a lifelong education, not just the professional type or re-education. It is for many prisoners the first opportunity to understand their history and to try to develop their own life project. The notion of prison education as a right is at the height of discussions around the world. In November 2006, for example, Brazil hosted the discussions in the Mercosur Educational Forum in Belo Horizonte, which had as one of the focus groups the Seminar on Prison Education, which received authorities on this issue from all Latin America and Europe And entities related to education and human rights. The objective was to create a Latin American network of discussions that would put prison education as the inalienable right of all and possible solutions to make this education more profitable.

Keywords: Prison Education; Mercosul; Recovery of Detainees.

\section{Topic: Direito Internacional}

Reviewed anonymously in the process of blind peer.

\section{Benigno Núñez Novo}

Universidad Autónoma de Asunción, Paraguai

http://lattes.cnpq.br/6452878036558472

benignonovo@hotmail.com
Received: 25/02/2016

Approved: 20/08/2016

\section{Referencing this:}

NOVO, B. N.. A educação prisional no Mercosul. Scientiam Juris, v.4, n.1, p.19-29, 2016. DOI: http://doi.org/10.6008/SPC2318$\underline{3039.2016 .001 .0002}$

DOI: 10.6008/SPC2318-3039.2016.001.0002 


\section{INTRODUÇÃO}

Rege a Declaração Universal dos Direitos Humanos: "Ninguém será submetido à tortura nem a tratamento ou castigo cruel, desumano ou degradante". Estes Tratados, Pactos e Convenções fazem parte dos ordenamentos jurídicos nacionais dos Estados, e são fontes soberanas de direito público, de plena e irrestrita vigência interna.

As normas definidoras dos direitos e garantias fundamentais têm aplicação imediata, isto é, são autoaplicáveis. Desta forma, os direitos e garantias não excluem outros decorrentes do regime e dos princípios adotados pelo governo brasileiro e constante nos tratados internacionais (Constituição da República Federativa do Brasil, parágrafos 1ำ e 2으, art. 5으 CF).

Nesse sentido, a Convenção de Viena, sobre Direito dos Tratados, de 1969, em seu artigo 60, prescreve como obrigação "erga ommes" que não se podem usar subterfúgios e invocações do direito interno para justificar o não-cumprimento de um Tratado aderido, nem a Constituição pode contradizer norma de Direito Público humanitário, vez que possui caráter imperativo ("ius congens") e não simples disposição.

Os Estados devem fazer valer a salvaguarda dos interesses comuns superiores protegidos pelas Convenções, para não afetar o seu próprio grau de validade hierárquica, sob forma de restrição ou de rebaixamento, mas sim, para aumentar os mecanismos de supervisão e respeito a um tratamento humano mínimo (ver Cançado Trindade, Antonio Augusto; in Direito Internacional Humanitário, IPRI, Brasília - 1989).

Dentre os Direitos Humanos dos presos, por exemplo, dispõe a Lei de Execução Penal brasileira (art. 10 e 10) que a sentença ou decisão criminal tem por objetivo proporcionar condições para a harmônica integração social do condenado e do interno, e que a assistência material, à saúde, jurídica, educacional, social e religiosa, é dever do Estado, para prevenir o crime e orientar o retorno à convivência do apenado em sociedade. Teoria do "res", segundo E.Raúl Zaffaroni, como justificativa ao encarceramento humano e restrição ao "ius libertatis".

"Nenhuma pessoa submetida a qualquer forma de detenção ou prisão será submetida à tortura ou a tratos ou penas cruéis, desumanas ou degradantes. Não se poderá invocar circunstância alguma como justificação da tortura ou de outros tratos ou penas cruéis, desumanas ou degradantes", estatui o princípio (6) do Projeto de Conjunto de Princípios para a Proteção de todas as pessoas submetidas a qualquer forma de detenção ou prisão da ONU (Resolução n. 43/173).

A expressão "tratos ou penas cruéis, desumanas ou degradantes" deve ser interpretada de maneira que abarque a mais ampla proteção possível contra todo tipo de abuso, sejam físicos ou mentais, incluído o de manter o preso ou detento em condições que o privem temporária ou permanentemente do uso de um de seus sentidos, como a visão ou a audição, ou de sua ideia de lugar ou do transcurso de tempo. (in La Revista, Por el Imperio del Derecho, da Comisión Internacional de Juristas, n. 42, Junio 1989).

O contido no artigo 1ㅇ Convenção Contra a Tortura da ONU, e dispositivo 2o da Convenção da OEA, rezam que "as dores e os sofrimentos por consequência de sanções legítimas ou "medidas legais", não estão compreendidos no conceito de tortura". Obviamente que devemos interpretar no sentido de que, desde não 
afetarem os princípios humanitários básicos. De outro lado, a execução da pena privativa de liberdade deve observar as Regras Mínimas das Nações Unidas para os detentos, do contrário pode caracterizar a prisão, na prática, pena infamante, cruel e desumana, visto que atenta contra a dignidade da pessoa encarcerada, ferindo inclusive os princípios elementares de justiça de um Estado Democrático de Direito.

Não devemos admitir e legitimar nenhuma das condições degradantes que estão sujeitos todos os presos, a prisão por si só causa dores, sofrimentos físicos e psicológicos nefastos e irreparáveis ao ser humano que o Estado pretende recuperar, ressocializar, reintegrar, reeducar ou readaptar.

É público e notório que a maioria, ou quase a totalidade, dos estabelecimentos prisionais da América Latina e do Brasil, efetivamente, tem transformado o cumprimento da pena privativa de liberdade, em sanção cruel e desumana. Ainda que esteja expresso em documento internacional que "nenhum funcionário encarregado de fazer cumprir a lei poderá infringir, instigar ou tolerar nenhum ato de tortura ou outros tratos ou penas cruéis, desumanas ou degradantes", reza o artigo 5o do Código de Conduta para Funcionários Encarregados de Fazer Cumprir a Lei (Adotado pela Assembleia Geral da ONU em 17-12-79 - Resolução n. 34/169).

Segundo a doutrina especializada, a expressão "funcionários encarregados de fazer cumprir a lei" inclui todos os agentes, nomeados ou eleitos, que exercem funções de polícia, com faculdades de arresto ou detenção, incluam-se, a nosso ver, também as autoridades judiciárias, magistrados que determinam a prisão e membros do Ministério Público que requerem a condenação à pena privativa de liberdade ou que postulam a prisão provisória.

Em geral, sabemos que a pena privativa de liberdade teve sua origem na revolução industrial e que seu objetivo foi e é eminentemente utilitário, ainda que o discurso ideológico tenha sido humanitário. Para isso, se faz indispensável o respeito a norma com rigidez em nome do princípio da legalidade.

O processo institucional de prisionalização gera fatores negativos, e estes são originários da: superpopulação; ociosidade; insalubridade e promiscuidade pela falta das mínimas condições de vida com dignidade e precariedade das instalações físicas. A violência física (sexual) e psíquica que estão sujeitos os detentos, a corrupção entre agentes penitenciários e grupos de internos, e muitas outras mazelas são produzidas dentro dos ergástulos públicos (ver CPIs do Sistema Penitenciário da Câmara dos Deputados Federais do Brasil, de 1975 e 1993).

Define a Regra 31 da ONU para Tratamento dos Reclusos, sobre disciplina e sanções: "As penas corporais, encerramento em cela escura, assim como toda sanção cruel, desumana ou degradante são completamente proibidas como sanções disciplinares". Se há previsão legal proibitiva de sanção disciplinar nestas condições, muito mais óbvio e evidente que o Poder Judiciário não pode admitir a execução da pena privativa de liberdade quando caracterize na prática sanção cruel, desumana e degradante.

Sabemos que os maus-tratos carcerários resultam do "modus vivendi" oferecido pelo Estado aos condenados à pena privativa de liberdade, que impera a "lei do mais forte" ou as sobrevivências no interior dos estabelecimentos penais. 
A regra geral do direito penal democrático é interpretar a lei restritivamente, e quando necessária a ampliação, esta maneira somente é autorizada juridicamente quando for em benefício ou a favor do réu ou do apenado. $\mathrm{O}$ artigo 3ำ do Código de Processo Penal, reforça este critério doutrinário, quando estabelece que são permitidas a aplicação dos princípios gerais do direito.

A título de estudo e de informação do direito positivo das Nações Unidas (Assembleia Geral em Resolução n. 40/43, de 29 de novembro de 1985), lembramos a recomendação do Sexto Congresso da ONU sobre Prevenção do Delito e Tratamento do Delinquente (Milão - Itália), para a continuidade do trabalho de elaboração das diretrizes e normas para as vítimas do delito de abuso de poder, solicitando a cooperação de organismos governamentais e não governamentais.

São consideradas "vítimas de abuso de poder" as pessoas que, individualmente ou coletivamente, tenham sofrido danos, inclusive lesões físicas ou mentais, sofrimento emocional, perda financeira ou diminuição substancial de seus direitos fundamentais, como consequência de ações ou omissões que não cheguem a constituir violações do direito penal nacional, mas violem normas internacionais reconhecidas e relativas aos Direitos Humanos (item 18, letra B, da Declaração sobre os Princípios Fundamentais de Justiça para as Vítimas de Delitos e do Abuso de Poder).

À luz dos instrumentos internacionais de Direitos Humanos, de aceitação universal e aderido pelo governo da República Federativa do Brasil, destacamos a Declaração Universal dos Direitos Humanos (1948/ONU); Pacto Internacional de Direitos Civis e Políticos (1966/0NU); Convenção Americana sobre Direitos Humanos (1969 / OEA); Regras Mínimas das Nações Unidas para Tratamento dos Reclusos (1955/57/77); Normas para a aplicação das Regras Mínimas para o Tratamento dos Reclusos (ONU/1984); Princípios Básicos para o Tratamento dos Reclusos (ONU/1990); Conjunto de Princípios para a Proteção de Todas as Pessoas submetidas a qualquer forma de Detenção ou Prisão (ONU/1988); e Regras Mínimas do Preso no Brasil (Ministério da Justiça/1994).

É de se ressaltar que na prática nenhum dos Documentos internacionais, muito menos a Constituição federal e a legislação ordinária positiva (Lei de Execução Penal) não estão cumpridas e respeitadas, dentro da obrigatoriedade dos princípios basilares do Estado de Direito, impõem-se às autoridades competentes e diretamente ligadas a questão prisional do país, seja na esfera do Poder Executivo (encarregadas do gerenciamento do sistema penitenciário), como na alçada do Poder Judiciário (competentes para a execução de medidas privativas de liberdade), responsabilidade criminal, em decorrência da inércia e/ou da prevaricação de atos de ofício que deveriam tomar e não o fizeram em tempo oportuno, conforme prevê o Código Penal (Decreto-lei n.o 2.848/40).

Os artigos 1ㅇe 10 da Lei n. 7.210/84, estabelecem que a execução penal tem por objetivo efetivar as disposições de sentença ou decisão criminal e proporcionar condições para a harmônica integração social do condenado e do internado. Ao condenado e ao internado serão assegurados todos os direitos não atingidos pela sentença ou da lei.

Carecem os detentos (provisórios e definitivos) do direito à assistência material, ou seja: de alimentação suficiente, vestuário, de atividades laborais (inclusive quanto à remuneração, previdência social 
e pecúlio, e direito de remição), intelectuais, artísticas e desportivas, à saúde, jurídica, educacional, social e religiosa.

Se a educação pode ajudar a reinserir um preso na sociedade, o Brasil está bem longe dessa meta. 0 sistema prisional brasileiro abriga 371.400 presos, de acordo com dados preliminares de 2006 do Ministério da Justiça. E menos de 10\% dos presos - 34 mil - completaram o ensino fundamental. Pior: cerca de 18 mil são analfabetos.

A Lei tem número, 7.210, é de 1984, se chama Lei de Execução Penal e é bem clara: determina a oferta do ensino fundamental e a formação profissional nas cadeias. Mas há uma enorme distância entre o que está escrito e o que realmente acontece dentro das prisões.

\section{DISCUSSÃO TEÓRICA}

\section{A Falta de Acesso à Educação}

Uma antiga máxima popular diz que "mente vazia é a oficina do diabo". Este provérbio não poderia ser mais adequado quando se trata da vida carcerária. O indivíduo privado de sua liberdade e que não encontra ocupação, entra num estado mental onde sua única perspectiva é fugir. O homem nasceu para ser livre, não faz parte de sua natureza permanecer enjaulado. Algumas raríssimas cadeias ainda oferecem certas condições que superam a qualidade de vida do preso se estivesse do lado de fora. Ainda assim, o sentimento de liberdade sempre é maior e mesmo estas cadeias acabam vivenciando rebeliões de fuga. Preso que não ocupa seu dia, principalmente sua mente, é um maquinador de ideias, a maioria delas, ruins. O presídio é um sistema fechado onde o encarcerado é obrigado a conviver, permanentemente, com outros indivíduos, alguns de índole igual, melhor ou pior. Nem sempre há cordialidade e animosidade é algo comum, gerando um eterno clima de medo e preocupação constantes, pois o preso nunca sabe se "o seu dia vai chegar". Grande parte desta angústia vivida pelo presidiário advém da falta de ocupação, de uma atividade que ocupe seu tempo, distraia sua atenção e que o motive a esperar um amanhã melhor. A ideia de todo presidiário é que sua vida acabou dentro das paredes da cadeia e que não lhe resta mais nada. Amparo psicológico é fundamental, pois nenhum ser humano vive sem motivação. Presídio sem ocupação se torna uma escola "às avessas": uma formadora de criminosos mais perigosos.

A grande maioria dos indivíduos presos não tiveram melhores oportunidades ao longo de suas vidas, principalmente a chance de estudar para garantir um futuro melhor. Nesse sentido, o tempo que despenderá atrás das grades pode e deve ser utilizado para lhe garantir estas oportunidades que nunca teve, por meio de estudo e, paralelamente, de trabalho profissionalizante. Além de ajeitar as celas, lavar corredores, limpar banheiros etc., os detentos precisam ter a chance de demonstrarem valores que, muitas vezes, encontramse obscurecidos pelo estigma do crime. Existem casos de detentos que demonstram dotes artísticos, muitos deles se revelando excelentes pintores de quadros e painéis de parede, além de habilidades com esculturas, montagens, modelagens, marcenaria etc. Também, decoram as celas de acordo com sua criatividade e sua personalidade. Estas artes devem ser incentivadas, pois é uma forma de ocupar o preso, distraindo-o e 
aumentando sua autoestima. É a chance de mostrar a ele de que existe a esperança de um amanhã melhor além das grades que o separam do mundo exterior.

No Brasil, o Ministério da Educação e o Ministério da Justiça trabalham juntos desde 2005 para criar uma política pública de educação prisional, com diretrizes nacionais. "Na maioria dos estados, existe educação nas prisões, mas de forma aleatória. Faltam vagas para os alunos interessados em estudar, nem sempre há todos os níveis. Há turmas de alfabetização e ensino fundamental, mas há alunos que gostariam de fazer o ensino médio também", diz Timothy Ireland. Ele conta que muitos presídios não dispõem sequer de espaço físico que comporte salas de aula. "Já vi até um corredor adaptado. A primeira parte era para turmas de alfabetização, a do meio para ensino fundamental e o fundo, para ensino médio. Tudo muito precário".

O diretor do MEC destacou as iniciativas argentinas, que desde 2003 tem uma política pública de educação prisional, segundo ele. "A forma de encarar a questão na Argentina é diferente dos demais países. Em vários, o assunto ainda não constitui uma política pública. Às vezes, [as ações] nem mesmo são feitas pelos governos, mas por ONGs".

A educação deve ser vista como um direito, não para a reintegração. Claro que isso é muito importante, mas se a reintegração for impossível, a educação continua a ser um direito. Não devemos instrumentalizar a educação unicamente para um papel social ou do tipo político-social. A educação pode ser uma solução se for uma educação ao longo da vida, não apenas do tipo profissional ou a reeducação. É para muitos presos a primeira oportunidade de compreender sua história e de tratar de desenvolver seu próprio projeto de vida.

A noção de educação prisional como direito está no auge das discussões em todo o mundo. Em novembro de 2006, por exemplo, o Brasil acolheu, em Belo Horizonte, as discussões do Fórum Educacional do Mercosul, que tinha como um dos núcleos de debates o Seminário de Educação Prisional, que recebeu autoridades neste assunto de toda a América Latina e Europa e de entidades ligadas à educação e direitos humanos. O objetivo era criar uma rede latino-americana de discussões, que colocasse na pauta dos governos de cada país a educação prisional como direito inalienável de todos e as possíveis soluções para tornar essa educação mais proveitosa. Os especialistas em educação prisional defendem que a escola deve ser um direito mesmo que o detento não seja reintegrado ou reintegrável à sociedade.

\section{A Educação Prisional no Mercosul}

No Paraguai segundo dados do Ministério da Justiça e Trabalho nas 15 (quinze) penitenciárias do país o número de presos são 5.889 dados estes de 12 de dezembro de 2008. O Paraguai apresenta uma das mais reduzidas percentagens de presidiários em relação à população (4 mil presos para 5,1 milhões de habitantes). No entanto, a maioridade penal é expressivamente baixa em relação aos outros países do continente: somente são inimputáveis criminalmente os menores de quatorze anos.

Em Tacumbu (maior presídio do país), é crônico o problema de superlotação. Por absoluta inexistência de espaço físico os presos vão ocupando todos os lugares disponíveis: a capela, a marcenaria, a 
cozinha, os escritórios administrativos e as dependências de assistência. São 1,5 mil pessoas aglomeradas, semelhante a um campo de refugiados. Esta grande concentração vem acarretando graves problemas de saúde e higiene. Não há incentivo ao trabalho penitenciário. Os telefones públicos, antes disponíveis no interior do presídio, foram barbaramente destruídos para obrigar os reclusos a alugar os aparelhos de telefonia celular daqueles que os possuem. Foram localizados também alguns presos provisórios entre os sentenciados. Um deles aguarda há oito anos decisão de seu processo criminal. A estes, além da ausência de assistência judiciária, não são observadas as orientações normativas de separação dos condenados, oferecimento de oportunidade de trabalho e muitas vezes são proibidas as visitas familiares. Próximo ao presídio de Tacumbu existe o Centro de Reabilitação chamado Panchito López, destinado a menores infratores, que abriga crianças e adolescentes de 14 a 18 anos. São trezentos reclusos divididos unicamente pelo critério de idade, o que expõe os menores a um risco potencial. Nem todas as celas estão em perfeito estado de conservação. O centro de Reabilitação carece de investimentos para ensino educacional e profissionalizante aos jovens de Tacumbu.

No Paraguai registram-se inúmeras queixas sobre a morosidade e a ausência de assistência jurídica. Por fim, constatamos ainda a incrível existência de um presídio fantasma, onde, embora existam diretores designados e previsão orçamentária, as obras para conclusão do presídio encontram-se em completo estado o de indiferença e abandono.

Em 2007 o Ministério da Educação e Cultura do Paraguai através da Direção Geral de Educação Permanente beneficiou com materiais escolares e didáticos cerca de 700 alunos da educação de média distância para jovens e adultos com ênfase para as novas tecnologias e 1000 estudantes da educação básica bilíngue para jovens e adultos. Este projeto é a implementação da Reforma Educativa da modalidade de jovens e adultos que se desenvolve em todo o país, através do Programa de Educação Básica Bilíngue de Jovens e Adultos (PRODEPA). O objetivo é melhorar a qualidade da educação dos presos e garantir o acesso a educação básica e de nível médio. O projeto aponta para o funcionamento e consolidação da nova rede de docentes penitenciários que conta com a estrutura e apoio para assegurar o processo de aprendizagem dos internos e a possibilidade de continuar seus estudos quando obtenham sua liberdade.

$\mathrm{Na}$ Argentina, há cerca de 30 mil reclusos, sendo que aproximadamente 6,1 mil pessoas cumpram pena em estabelecimentos federais de Buenos Aires. De acordo com os dados oficiais, apenas $20 \%$ da população carcerária argentina encontra-se contemplada pelo direito ao trabalho penitenciário. É também alarmante a informação de que aproximadamente $8 \%$ dos reclusos estariam infectados pelo vírus da Aids, fato este agravado pela grande incidência de outras doenças sexualmente transmissíveis.

No presídio federal Caseros, em plena Buenos Aires, centenas de presos condenados não têm onde tomar sol ou praticar esportes. Não há a menor perspectiva de trabalho num presídio parcialmente destruído pela última rebelião, ocorrida já há alguns anos.

O melhor exemplo de administração penitenciária da Argentina foi observado em Olmos, próximo a La Plata. Lá encontramos 3.336 internos, dos quais 80\% são sentenciados. Embora a população carcerária seja superior à sua capacidade, Olmos apresenta alguns aspectos positivos: aos detentos são oferecidos 
serviços de ensino integrado à rede pública educacional. São 180 reclusos matriculados em curso primário e 220 em aulas de orientação secundária. Em todos os pavilhões são encontrados telefones públicos que permitem aos presos o livre acesso a seus familiares e advogados. Um serviço comunitário de rádio opera internamente, ocupando parcialmente a população carcerária. É permitida a visita conjugal aos detentos, bem como assistência religiosa. Durante a visita tivemos a oportunidade de presenciar uma cerimônia pentecostal que reuniu cerca de oitocentos detentos.

No Uruguai - bastião do civismo, da melhor distribuição de renda do continente e dos direitos sociais - é o Ministério do Interior responsável tanto pela repressão ao crime e quanto pelo encarceramento, em contradição à regra fundamental de incompatibilidade entre as duas atribuições.

O Complexo Carcerário Santiago Vásquez, que aloja mais de $50 \%$ da população reclusa do país. Constata-se o problema de superlotação, já que, originariamente concebido para alojar oitocentos presos, hoje comporta 1,7 mil detentos. Há ainda grande carência em matéria de trabalho, apesar de alguns convênios realizados com empresas privadas. Um problema essencial é a inexistência de hospital penitenciário para atendimento médico, farmacêutico e ambulatorial.

Em muitos países, a remição já é lei há décadas. “Por trás da remição, está o conceito de prisão, que ou tem uma perspectiva de punição ou uma visão de ressocialização. Nós a vemos como forma de reintegrar à sociedade, por isso a educação pode acelerar esse processo de soltura do condenado", diz Hernando Lambuley, chefe da divisão de desenvolvimento social do Instituto Nacional Penitenciário e Carcerário da Colômbia. Na Colômbia, a cada cinco dias de aula, um a menos de pena a cumprir.

No Equador, a conta é sete dias de estudo igual a um de pena cumprida. No entanto, a remição não vale para assassinos e narcotraficantes. "Estes não têm esse direito em função da gravidade do delito", explica Eduardo Chiliquinga, coordenador-geral do Ministério da Educação e Cultura do Equador.

A educação nas prisões acaba de ser incorporada na nova Lei Nacional de Educação Argentina. Lá, o estudo funciona apenas como sinônimo de bom comportamento, mas não há equivalência estabelecida de dias estudados em troca de pena cumprida. "O estudo é valorado como boa conduta, como alguém que está interessado em mudar de rumo na vida", diz Stella.

O panorama hoje nos mostra uma realidade que desencadeia na reclusão de muitíssimas pessoas que criminalizam suas atitudes, suas intenções, seus atos, seus agires, e desta maneira contaminam outros seres que ficam possuídos pelo medo, esse que é o pior inimigo do homem, esse que não deixa a paz e a segurança interna se desenvolver para impulsionar os desejos particulares e converter-Ihes em realidade. Privações à liberdade ficam ganhando como prêmio pelos seus comportamentos, e a sociedade em geral acredita ser uma bela punição esta perda no direito de ir e vir, pois acontece que o estado em que se encontram os condenados ao cárcere evidencia de por si a carga da pena que desta maneira lhes parece ser o melhor dos castigos, mas esquecemos dos direitos de todos os que são privados da suas liberdades e que merecem, a pesar da sua conduta reprovável e ilegal, um tratamento adequado, pois é letrado no Pacto Internacional dos Direitos Civis e Políticos das Nações Unidas com entrada em vigor na ordem internacional 
em 23 de Março de 1976: "Art.10. Todos os indivíduos privados na sua liberdade devem ser tratados com humanidade e com respeito da dignidade inerente à pessoa humana".

Claro que também ficam privados de liberdade, os que foram vítimas destas violações, pois são cada vez mais janelas de carros fechadas, muros mais altos são construídos em casas, mais temores inculcados na infância das nossas crianças, mais alerta de cuidados para aos nossos visitantes vindos de outros países e que taxam as nossas belezas como envenenadas pela falta do livre desfrute de quem vem de longe para deixar suas divisas e levar em troca a fama da insegurança total, da pobreza e do despreparo educacional.

Os homens e mulheres de boa-fé devem se inter-relacionar em harmonia e com cortesia, e devemos nos esforçar para que nas próximas décadas o nosso país seja reflexo de intenção em um sentido de melhorar tudo o que está se encontrando como desviado e prejudicial para o desenvolvimento de uma humanidade mais consciente das suas atitudes; mais consciente dos limites que a lei impõe para organizar uma sociedade frutífera, produtiva e cheia de possibilidades para todos. Também devemos cobrar ao Estado para que através dos nossos governantes sejam promovidas políticas públicas de inclusão social, que possibilite a todos o mínimo necessário para a formação do cidadão.

Os que entendem que a vida é uma oportunidade que a existência nos dá para o crescimento pelo bem estar, de uma maneira mais consciente com a responsabilidade pessoal e individual como célula da sociedade, figurando-se mais aptos para adquirir tolerância e um entendimento de que as forças devem ser unidas em grupos organizados na comunidade acadêmica que como sementes luminosas, dentro da obscuridade que o crime encerra, se instalem e criem raízes fortes para castrar o crescimento e formação de futuros desgostos.

Nota-se que precisamos de uma estrutura carcerária mais digna como pretende o texto constitucional da ensaiada Constituição para a América Latina e o Caribe, esboçada pelo Movimento Constitucional Latino Americano da Equipe Federal do Trabalho no seu Capítulo IV, Dos Cárceres dignos:

Art.78. Todos os Estados integrantes da União assegurarão que os cárceres dentro de cada território sejam: sãos, limpos, seguros, tutores do direito à integridade física, psíquica e moral, guardiões da honra e dignidade, patrocinadores dos direitos constitucionais dos internos; educativos, antecipando-se, observando e aplicando obrigatoriamente a estes as ferramentas de socialização e reinserção necessárias. Os cárceres não serão um meio de castigo ou perseguição física, psicológica ou moral para seus internos, nem por parte do serviço penitenciário nem por parte de outros internos. Qualquer violação destes direitos tornará responsável a quem o permitir ou autorizar.

É dessa responsabilidade que deve estar imbuídos todos os que acreditam em uma filosofia de vida em prol de uma sociedade melhor, de perfil inclusivo e de respeito à dignidade da pessoa humana, é aqui quando temos que assimilar que a capacidade de ler as realidades políticas é vital para a montagem de coligações e redes por trás dos bastidores. Essas redes permitem a alguém exercer influência, independentemente de seu papel profissional. Os que têm um desempenho medíocre carecem dessa acuidade social e por isso revelam um nível tristemente baixo de sabedoria política.

Deve-se buscar estudar as ciências criminais também como uma chave que pode abrir caminhos para parar o sofrimento de muitos que sofrem; buscar uma sabedoria política que deve ser carregada da política 
da empatia na medida certa para muitos que sofrem como todos nós sofremos pelos infortúnios resultantes na nossa humanidade em geral por causa das escolhas más, das escolhas de seres que geram estados dignos de compaixão e que estão contaminados pelo seu próprio ódio e frustração, e que às vezes, nunca tiveram uma chance de aprender a arte de viver, de viver em paz consigo mesmo e, porém com os outros seres vivos.

Há várias décadas existe uma experiência que é vivida no Sistema Penitenciário da República da Índia, especificamente na prisão de Tihar, Nova Delhi, e em mais de quinze prisões desse país, e mais recentemente nesta última década nos países de Israel, no Presídio para Mulheres na Mongólia, em Taiwan, na Espanha, na Grã-Bretanha, nos Estados Unidos, México, Chile e Argentina, sendo que o Brasil já se mostra interessado em também adotar esta, poderíamos dizer, ferramenta de reestruturação do sistema prisional.

As pessoas importantes são os agentes penitenciários que se relacionam com os detentos cotidianamente. São eles que abrem as celas dos detentos pela manhã, que ficam junto deles a maior parte do dia e que os encerram pelas noites. São testemunhas das maiores forças e das grandes debilidades dos detentos. A forma como os agentes penitenciários tratam os detentos determinará se uma prisão é decente e humana, ou brutal e coercitiva. Eles falam com os reclusos habitualmente, seja com respeito ou não, controlam a distribuição das camas e das celas, o acesso às comidas, às visitas familiares, às encomendas, às correspondências, o acesso aos telefones, ao trabalho, à educação, aos médicos e aos traslados para outras prisões.

São os agentes penitenciários que mitigam as desordens potenciais, manejam os incidentes com toma de reféns, fazendo isto de forma violenta ou por médio de uma negociação. Para que os agentes penitenciários tratem bem aos detentos e respeitem seus direitos, é essencial que eles mesmos sejam respeitados e valorizados. Também necessitam se desenvolver dentro de um marco ético claramente estabelecido e valorizado publicamente e que defina os parâmetros das condutas aceitáveis.

A formação e treinamento são necessários para melhorar o profissionalismo e as aptidões dos agentes penitenciários, mas também para deixar em claro que as autoridades superiores considerem que um maior profissionalismo dos agentes penitenciários é um investimento importante. Normalmente quem apoia um projeto de reforma penitenciária soe considerar que dar uma formação adicional aos agentes penitenciários constitui uma das melhores formas de aperfeiçoar a administração das prisões e garantir um maior respeito pelos direitos humanos.

Mudar as condutas e atitudes dos agentes penitenciários é chave para o sucesso da reforma penitenciária, assim considerando que a reforma é a solução. Se prestando, também, atenção a outros fatores importantes para os agentes penitenciários, como os são suas condições de emprego e o acesso a diversos recursos como o da possibilidade da formação educativa, intelectual e religiosa que lhes permitam o respeito e a valorização pelos seus direitos e pelos direitos dos demais. Podemos afirmar que a maneira em que os agentes penitenciários tratam os detentos é fundamental para o respeito dos direitos humanos. 


\section{CONCLUSÃO}

A relevância da educação prisional como instrumento de ressocialização e de desenvolvimento de habilidades e de educação para a empregabilidade é notória no sentido de auxiliar os reclusos a reconstruir um futuro melhor durante e após o cumprimento da sentença. Os objetivos de encarceramento ultrapassam as questões de punição, isolamento e detenção. A educação auxilia e permite a obtenção dos objetivos centrais de reabilitação que incidem em resgate social e educação libertadora numa dimensão de autonomia, sustentabilidade e minimização de discriminação social. Trabalhar na busca da identidade perdida, e participar desta sociedade modernizada e midiatizada, poderá ser um viés articulador e um grande desafio para gerar mudanças, compromissos e possibilitar aos reeducandos um retorno digno à sociedade.

\section{REFERÊNCIAS}

ADORNO, S.. A Prisão sob a ótica de seus protagonistas: Itinerário de uma Pesquisa. Tempo Social; Rev. de Sociologia da USP, São Paulo, v.3, n.1-2, p.7-40, 1991.

ANISTIA INTERNACIONAL. Brasil: aqui ninguém dorme sossegado: violações dos direitos humanos contra detentos. São Paulo, 2002.

ARANHA, M. L. A.. História da educação. 2 ed. São Paulo: Moderna, 1998.

BECKER, H. S.. Métodos de Pesquisa em Ciências Sociais. São Paulo: Hucitec, 1997.

BRANDÃO, Z.. Entre questionários e entrevistas. In: Pesquisa em Educação: conversas com pós-graduandos. Rio de Janeiro: PUC-Rio; São Paulo: Edições Loyola, 2002.

BRANDÃO, D. M. S.; CREMA, R.. Visão Holística em Psicologia e educação. São Paulo: Summus, 1991.

BRASIL. Constituição (1988) Constituição da República Federativa do Brasil. São Paulo: TR, 2000.

BRASIL. Lei № 9.394, 20 dez. 1996. Diretrizes e Bases da Educação Nacional. Brsilía: DOU, 1996.

Buarque, C.. Qualidade de vida: a modernização da utopia. Revista Lua Nova, São Paulo, n.31, p.157-165, 1993.
CAPELLER, W.. O Direito pelo avesso: análise do conceito de ressocialização. Temas IMESC, Soc. Dir. Saúde, São Paulo, v.2, n.2, p.127-134, 1985.

FOUCAUL, M.. Vigiar e punir: nascimento da prisão. 35. Petrópolis: Vozes, 2008.

MIRABETE, J. F.. Lei de execução penal. 5 ed. São Paulo: Atlas, 1993.

MOORE, M. G.. Distance education: a systems view. 1996.

MORAN, J. M.. Novas Tecnologias e Mediação Pedagógica. São Paulo: Papirus, 2000

MORIN, E.. Os sete saberes necessários a educação do futuro. São Paulo: Cortez, 2000.

NEVES, C. M. C.. TV na Escola e os desafios de hoje: tecnologias e educação: desafios e a TV escola. Brasília: EAD/SEED, 2000.

OLIVEIRA, E.. O Futuro Alternativo das Prisões. Rio de Janeiro: Forense, 2001.

OLIVEIRA, O.M.. Prisão: um paradoxo social. 2 ed. Florianópolis: DAUSFC, 1996.

VASCONCELLOS, C. S.. Construção do conhecimento em sala de aula. 8 ed. São Paulo: Libertad, 1999. 